\title{
An explorative study to enable environmentally conscious manufacturing for an industrial gearbox manufacturing organization
}

\author{
Parag Sen ${ }^{1,2, *}$, Parimal $\mathrm{Pal}^{2}$, and Mousumi Roy ${ }^{3}$ \\ 1 Department of Industrial and Systems Engineering, Indian Institute of Technology, Kharagpur 721302, India \\ 2 Department of Chemical Engineering, National Institute of Technology, Durgapur 713209, India \\ 3 Department of Management Studies, National Institute of Technology, Durgapur 713209, India
}

Received 19 September 2014 / Accepted 3 November 2014

\begin{abstract}
In recent years, environmentally conscious manufacturing (ECM) has become an important aspect and proactive approach for majority of the manufacturing organizations in India. The reason is that ECM not only helps to produce environment friendly, but also helps to make money by reducing cost or achieving competitive advantage. Industrial gearbox manufacturing organizations have significant environmental impacts as industrial gearbox manufacturing involves several steps which use valuable resources and pollute the environment. Hence, this paper presents an explorative environmental study of an Indian industrial gearbox manufacturing organization. The objective of the current paper is (i) to identify the environmental problems and environmentally conscious manufacturing indicators (ECMI), (ii) to find out the root causes of these problems and (iii) to solve the root causes based on the available stateof-the-art literature. This research work not only reviews the efficient environment friendly manufacturing techniques, but also helps the organization to become eco-efficient by producing environment friendly while making money. First ECMIs selected from literature review, are validated through process mapping. Then these indicators are prioritized using analytic hierarchy process (AHP) to find out the critical environmentally conscious manufacturing indicators (CECMI). The sources of CECMIs are identified using either data envelopment analysis (DEA) or direct observation of the available database. Finally, some possible solutions are also addressed in this paper.
\end{abstract}

Key words: Environmental conscious manufacturing, Industrial gearbox manufacturing, Environmentally conscious manufacturing indicators, Analytic hierarchy process, Data envelopment analysis

\section{Introduction}

Environmental conscious manufacturing (ECM) has been the focus of considerable attention over the past few decades developing and implementing technologically and economically viable products, processes and systems to promote human welfare and the biosphere with making money [1]. ECM may also lead to prevent global warming and climate change by reducing the carbon footprint of a defined population, system or activity, considering all relevant sources, sinks and storage within the spatial and temporal boundary of the population, system or activity of interest [2]. There may be a number of good reasons to get involved in taking action on this matter from the industrial perspective, like to reduce cost with increased revenue, minimizing the risks associated with higher energy costs and extreme weather events affecting the supply

*e-mail: paragbelurmath@gmail.com of goods or customers [3]. Global and domestic environmental laws, rules and regulations are forcing many organizations to produce environment friendly considering environmental impacts of all functions, business processes and products [4, 5].

In India, the Central Pollution Control Board (CPCB) is taking initiatives to protect the environment, identifying the large and medium scale industries in 17 categories based on the contributing potentiality of maximum pollution load. Manufacturing organizations are forced to install necessary pollution control equipments to comply with the prescribed standards. National River Conservation Authority (NRCA) is also taking initiatives against the polluting industries that are directly discharging their effluents into rivers and lakes, without proper treatment. A centrally sponsored scheme has been undertaken for enabling the small scale industries to set-up common effluent treatment plants in the country since majority of the polluting small scale industries are unable to afford installation of pollution control equipments due to limited financial resources. In order to exchange 
or reuse the wastes, adopt latest technologies, share physical resources and produce environment-friendly, clustering concept is employed for the manufacturing industries. ECM programmes are executed all over India to reduce environmental damage and rapid deletion of natural resources. Industrial gearbox manufacturing industries are also considering ECM programmes to become eco-efficient [6-9].

With today's global awareness of environmental risks as well as the pressing needs to compete through efficiency, manufacturing systems including industrial gearbox manufacturing are evolving into a paradigm of environmentally conscious manufacturing to employ various environment-friendly strategies and techniques in order to become more eco-efficient. Gear manufacturing industries may be considered essential to the global economy as gears are used in nearly all applications where power transfer is required, such as automobiles, aeroplanes, helicopters, marine vessels and industrial equipments [10]. Making an industrial gearbox using fewer resources is a good strategy to make money with reducing environmental footprint $[1,11,12]$.

ECM programmes for industrial gearbox manufacturing organizations essentially consider air, water and noise pollution generated in different manufacturing processes of gearbox. ECM also considers energy consumption during different manufacturing processes. Industrial gearbox manufacturers must focus to eliminate wastes during the manufacturing process to reduce costs and protect environment. The demand for cleaner, more environmentally friendly lubricant technology may also play an important role in gearbox manufacturing technology development. In addition to environmental impact during operation, gear manufacturers also need to consider the impact of the gearing systems at the end of service as customers are likely to demand greater recyclability of gear systems and wastes, including spent lubricants and the use of recyclable gear materials. From the perspective of environmental considerations, gear manufacturers should increase their focus on innovation particularly in the manufacturing process to remain costcompetitive in the global industrial gear market [1,10,13-15].

Since industrial gearbox manufacturing deals with several complex environmental issues, an explorative study is required to understand the environmental problems and their sources or root causes. Information about rest of the paper is organized as follows. Literature review is discussed in Section 2. Study methodology is provided in Section 3. Case study is discussed in Section 4 and the conclusion section is provided in Section 5.

\section{Literature review}

Several researchers consider air pollution, water pollution, waste generation, noise pollution and energy consumption to address the environmental problems for industrial gearbox manufacturing organization. ECM programmes may help industrial gearbox manufacturing organizations to minimize these pollutions. Improving environmental performance not only protects the natural environment but also prevents rapid repletion of natural resources. Environmentally conscious gearbox manufacturing may help to improve economic performance and achieve competitive advantage with increased customer satisfaction [16-18].
Air pollution for an industrial gearbox manufacturing organization is essentially measured by stack emission characteristics and fugitive air characteristics. Stack emissions refer to emissions discharged from stack. The major types of stack emissions are concentration of particular matters, concentration of carbon dioxide $\left(\mathrm{CO}_{2}\right)$, quantity of gas flows, quantity of particulate matters discharged and fuel consumption. Fugitive source air emissions are distributed over a wide range of area and not confined to a specific discharge point and may originate in operations where exhausts are not captured or passed through a stack. Fugitive emissions impact more on ground level as they are discharged and dispersed close to the ground. The major types of fugitive emissions are suspended particular matters (SPM), residual particular matters (RPM), sulphur dioxide $\left(\mathrm{SO}_{2}\right)$, and nitrogen oxide $\left(\mathrm{NO}_{\mathrm{X}}\right)$. Proper measurement methods are required to measure and monitor ambient air quality of an industrial gearbox manufacturing organization $[19,20]$.

Wastewater discharged by a gearbox manufacturing organization contribute significantly to pollute water as it may involve high biological oxygen demand (BOD) and chemical oxygen demand (COD). BOD is the amount of dissolved oxygen needed by aerobic biological organisms in a body of wastewater to break down organic material present in a given wastewater sample at certain temperature over a specific time period. COD determines the amount of organic pollutants found in wastewater. Wastewater or effluent should be treated before they are discharged into water bodies. Quality of discharged water should be monitored properly and frequently. Segregation of waste water streams may help in reducing waste water volume and strength [7, 21]. Regarding solid wastes also proper disposal techniques may be required. Recycling and downcycling (converting waste materials to new materials of less quality or functionality compared to the virgin material) are focused by the researchers and practitioners to use the solid wastes efficiently [4, 22].

In case of noise pollution, industrial gearbox manufacturing may generate high level of noise, causing occupational problems to the workers. Noise pollution should be taken care of as it may cause temporary and permanent hearing loss. It may also disrupt communication, cause fatigue, stress and anxiety reducing efficiency and job performance. The maximum permissible sound pressure level for diesel generator sets with rated capacity upto $1000 \mathrm{KVA}$ may be considered as $75 \mathrm{~dB}(\mathrm{~A})$ at the distance of $1 \mathrm{~m}$ from the enclosure surface. For the diesel generator sets, integral acoustic enclosure is required to prevent noise pollution. During industrial gearbox manufacturing, noise mainly generates from grinding and machining shop. Different precautions are highlighted by the researchers to prevent the noise $[23,24]$.

Need of efficient energy use in manufacturing is focused by different researchers and practitioners. Efficient energy use not only reduces energy consumption, but also directly and indirectly controls greenhouse gas (GHG) emissions [25, 26]. For less energy intensive sectors energy efficiency strategies is needed due to the wider range in energy uses within these sectors. Industrial gearbox manufacturing is not highly energy intensive like petrochemical or iron and steel sector. However, eco-design framework and energy coefficient 
approach may benefit industrial gearbox manufacturing organization to reduce energy consumption. Fuel mix may be considered as an important strategy to reduce the requirement of fuel, hence net cost. Energy efficient lights and machines may help an industrial gearbox manufacturing organization to save money significantly [27-29].

Though a number of researchers and practitioners discuss about environmentally conscious gearbox manufacturing, however prioritization of the environmental conscious manufacturing indicators (ECMI) are not focused by the researchers. The sources or root causes of CECMIs are also need to be identified. Otherwise instead of having state-of-the-art literature industrial gearbox manufacturing organization will not be able to implement the state-of-the-art techniques.

\section{Study methodology}

In this section, an integrated and holistic framework is provided (where rectangles indicate different phases/steps and ovals represent sources/tools/techniques) as study methodology for the current case study (see Figure 1). This study methodology consists of four phases as follows:

Phase 1: Identification and validation of ECMIs through process mapping

Initially the ECMIs may be chosen from literature review. Then they are validated through process mapping to understand which particular indicators are to be considered to produce environment friendly for the present industrial gearbox manufacturing organization. Direct observation and opinion of experts are required for process mapping.

Phase 2: Identification of ECMIs using analytic hierarchy process (AHP)

After validation of the ECMIs, they are subjected to analytic hierarchy process (AHP) to apply group decision making avoiding the biasness among the decision makers. AHP has the ability to quantify both objective and subjective judgments in order to make a trade-off to determine the priority weights. This will help to find out critical environmentally conscious manufacturing indicators (CECMI) based on the ranking of the ECMIs. The steps for AHP to be followed after selecting the experienced experts are as follows [30, 31]:

Step 1: Pairwise comparison is the first stage for AHP method to categorize the experts' view from 1 (equal importance) to 9 (extreme inequality in importance). In this step one indicator is compared with another indicator with respect to the objective of environmentally conscious manufacturing.

Step 2: Calculation of local priority vectors including checking consistency is the second step for AHP, which may be obtained using the following equation; $Z, m$ and $\lambda_{\max }$ being the matrix of pairwise comparison values, priority vector or principal eigenvector and maximum or principal eigenvalue of matrix $Z$.

$$
Z m=\lambda_{\max } m
$$

The consistency ratio is used to check whether the judgments of the decision makers follow logic or just putting some random numbers. The consistency ratio (CR) is given by the following equation where CI, RI and $n$ being the consistency index, random index and size of matrix $A$ respectively.

$$
\mathrm{CR}=\frac{\mathrm{CI}}{\mathrm{RI}} \quad \text { with } \quad \mathrm{CI}=\frac{\lambda_{\max }-n}{n-1}
$$

A consistency ratio of less than 0.10 or $10 \%$ may be acceptable, otherwise in case of higher CR, the decision makers have to consult again to modify their judgment. The values for RI may be obtained from the following table (see Table 1).

Phase 3: Identification of the root causes of CECMIs

After identifying the CECMIs, the sources or root causes are to be identified to understand each problem area. This may be determined by using data envelopment analysis (DEA) or direct observation of the database.

DEA is a nonparametric method originally developed by Chares, Cooper and Rhodes based on linear programming (LP) used to calculate relative technical efficiency for a set of alternatives (sources) where each alternative (source) is known as decision making unit (DMU). A DMU is defined as the tangible or intangible asset responsible for transforming a set of inputs into outputs, whose performance is supposed to be evaluated. The number of DMUs should not depend on the number of inputs and outputs combined to apply DEA model, because DEA is used as a benchmarking tool focusing on the performance of individual DMU [32]. In DEA model, if an indicator is desired to have greater value (i.e. higher is better), it may be considered as an output and if an indicator is desired to have smaller value (i.e. lesser is better), it may be considered as an input. Most popular two types of DEA models are constant return to scale or CRS (or CCR) model and varying return to scale (or BCC) or VRS model which are described below.

CRS model considers that there is no assumption that any positive or negative economies of scale exist. The relative efficiency for CRS model may be expressed as follows [33, 34]:

$$
\begin{gathered}
E_{k s}=\text { Weighted sum of outputs/Weighted sum of inputs } \\
\qquad E_{k s}=\frac{\sum_{y} O_{s y} v_{k y}}{\sum I_{s x} u_{k x}}
\end{gathered}
$$

where $E_{k s}$ is the efficiency of source $s$, using the weights of "test" source $k$, where the test EP is the unit whose efficiency is to be evaluated; $O_{s y}$ is the value of output $y$ for source $s ; v_{k y}$ is the weight assigned to source $k$ for output $y$; $I_{s x}$ is the value for input $x$ of source $s$; and $u_{k x}$ is the weight assigned to source $k$ for input $x$.

As per the envelopment model, the objective is to maximize the efficiency value of a test source $k$, from a reference set of sources $s$, by selecting the optimal weights associated with the input and output measures and may be expressed as follows:

$$
\begin{gathered}
\text { Maximize } E_{k k}=\frac{\sum_{y} o_{k y} v_{k y}}{\sum I_{k x} u_{k x}} \text { subject to: } E_{k s} \leq 1 \forall \text { source } s \\
u_{k x}, v_{k y} \geq 0
\end{gathered}
$$




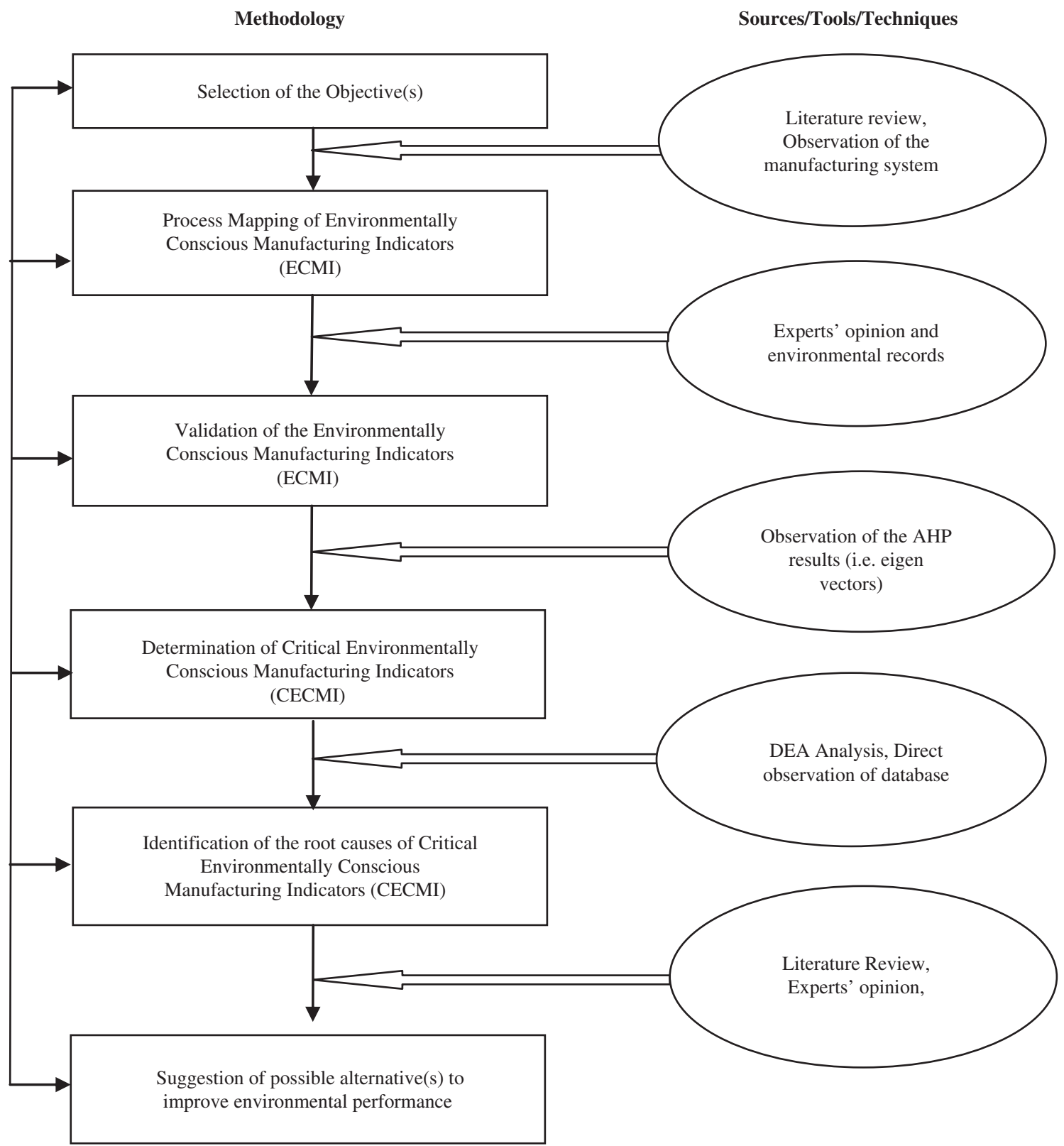

Figure 1. Methodological framework for explorative environmental study of an Indian industrial gearbox manufacturing organization.

Table 1. Values for Random Consistency Index (RI).

\begin{tabular}{ccccccccccc}
\hline$n$ & 1 & 2 & 3 & 4 & 5 & 6 & 7 & 8 & 9 \\
\hline R.I. & 0 & 0 & 0.52 & 0.89 & 1.12 & 1.26 & 1.36 & 1.41 & 1.46 & 1.49 \\
\hline
\end{tabular}

This nonlinear programming formulation may be considered as equivalent to the following linear programming formulation:

$$
\begin{gathered}
\text { Maximize } E_{k k}= \\
\sum_{y} O_{k y} v_{k y} \text { subject to: } E_{k s} \leq 1 \forall \text { source } s \\
\sum_{x} I_{k x} u_{k x}=1 \text { and } u_{k x}, v_{k y} \geq 0
\end{gathered}
$$

Optimal "technical efficiency value" $\left(E_{k k}^{*}\right)$ is the result of formulation (12) which is at most equal to one. If $E_{k k}^{*}=1$, no other source is more efficient than source $k$ for its selected weights, keeping source $k$ on the optimal frontier. If $E_{k k}^{*}<1$, at least one source is more efficient than source $k$ for the optimal set of weights. In other words, a DMU is considered efficient when no other DMUs can produce more outputs using an equal or lesser amount of inputs. The formulation (12) may be executed $s$ times, once for each source. Using simpler notation as used (12) may be written as [35]:

$$
\begin{gathered}
\operatorname{Max}(u, v)=O u_{k} \\
-u x+v y \leq 0 \text { subject to: } u x_{k}=1 \text { and } u, v \geq 0
\end{gathered}
$$


Before solving, the linear program may be converted to its dual for efficiency as follows:

$$
\begin{gathered}
\operatorname{Min}(\theta, \lambda)=\theta \\
\theta x_{k}-x \lambda \geq 0 \text { subject to: } y \lambda \geq y k \text { and } \lambda \geq 0
\end{gathered}
$$

Adding slack variables (for output shortfall and input overconsumption compared to the efficient frontier) the dual problem may be written as:

$$
\begin{gathered}
\operatorname{Min}(\theta, \lambda)=\theta \\
\theta x_{k}-x \lambda=\psi^{-} \text {subject to: } y \lambda=y_{k}+\psi^{+} \\
\text {and } \lambda, \psi^{+} \psi^{-} \geq 0
\end{gathered}
$$

In CRS model, it is assumed that one alternative is able to operate as efficiently as other alternatives (i.e. means constant returns to scale). To address this problem a flexible version of DEA is developed by Banker, Charnes and Cooper allowing variable returns to scale or VRS (i.e. either increasing return to scale [IRS] or decreasing return to scale [DRS]).

VRS model is related to the standard CRS model as is evident in the dual of the VRS model:

$$
\begin{gathered}
\operatorname{Min}(\theta, \lambda)=\theta \\
\theta x_{k}-x \lambda=\psi^{-} \text {subject to: } y \lambda=y_{k}+\psi^{+}, e \lambda=1, \\
\text { and } \lambda, \psi^{+} \psi^{-} \geq 0
\end{gathered}
$$

The difference compared to the CRS model is the introduction of additional constraint considering convexity condition $e \lambda=1$ and hence leading the frontiers to achieve piecewise linear and concave characteristics.

Phase 4: Suggestion of possible alternatives

After identifying the CECMIs, the final step is to suggest possible cost effective alternatives to improve the environmental performance of the current industrial gearbox manufacturing organization. These solutions must meet the rules and regulations and demands as imposed by the stakeholders.

\section{Case study}

A case study of an industrial gearbox manufacturing organization is illustrated in this section to enable environmentally conscious manufacturing. This section is further divided into six sub-sections which are described as follows:

\subsection{Company profile}

The industrial gearbox manufacturing organization is a small and medium scale enterprise (SME) specialized in manufacturing worm gearbox, helical gearbox and geared motor. Industrial gearbox is an enclosed system of assembled gears, capable to change its speed, direction and torque, in order to transmit mechanical energy from a prime mover to an output device. While worm gearbox consists of worm wheel, worm shaft and wheel shaft, helical gearbox consists of housing, helical gear or spur gear and pinion shafts. In case of geared motor, co-axial shaft gearbox without input shaft assembly is fitted with electric motor either in coaxial or off-set position with one or two gearbox casings in order to provide compact power pack units without any other rotating member such as coupling. Geared motors, ranging output power from 0.12 to $40 \mathrm{HP}$, are manufactured to generate a speed ranging from 0.16 to $780 \mathrm{rpm}$. The company makes gear sets of any reduction ratio for in-house manufacturing of hob cutters. Manufacturing operation of the organization is carried out by a team of professionally competent technocrats and other professionals who are also responsible to produce environment friendly.

\subsection{Basic manufacturing process}

Manufacturing process of an industrial gearbox involves a number of stages like machining (turning, milling or thread cutting, slotting, hobbing or gear cutting etc.), heat treatment (carburizing, hardening and quenching), grinding and assembling (where rectangles indicate manufacturing steps and ovals represent parts/products) (see Figure 2). The basic raw materials used for the manufacturing process are (i) bar without disc, (ii) forged and proof machined disc and bar, and (iii) housing. This plant consists of four shops, namely machining shop, heat treatment shop, grinding shop and assembling shop.

Machining process deals with controlled material-removal process whereas heat treatment (involves carburizing, hardening and quenching) is used to alter the physical and chemical properties of material in order to achieve high strength, toughness and resistance to shock. Heat treatment shop produces considerable amount of green house gases (GHG) such as carbon dioxide, methanol, acetone vapor etc. Grinding is a surface finishing operation performed with a rotating abrasive wheel to produce high surface quality with accuracy of shape and dimension. Grinding shop, too, produces a significant amount of GHGs for its use of cutting fluids. For machining and grinding purpose, the organization uses conventional as well as computerized numerical control (CNC) machines. Assembling is the final operation to comprise a number of mating parts or subassemblies to produce the finished products.

\subsection{Process mapping}

From literature review it is preliminarily observed that stack emission characteristics (I1), fugitive air characteristics (I2), wastewater characteristics (I3), solid waste generation level (I4), noise intensity level (I5) and energy consumption (I6) may be considered ECMIs for industrial gearbox manufacturing. In order to validate, these indicators are mapped with respect to the manufacturing stages (see Tables 2-4; along with the help of the concerned experts) to understand whether these indicators are really considerable for the current industrial gearbox manufacturing organization.

\subsection{Identification of the CECMIs using analytic hierarchy process (AHP)}

To enable AHP, first three experienced decision makers (environmental manager, production manager and energy manager) who have above 15 years of experience are asked to do 


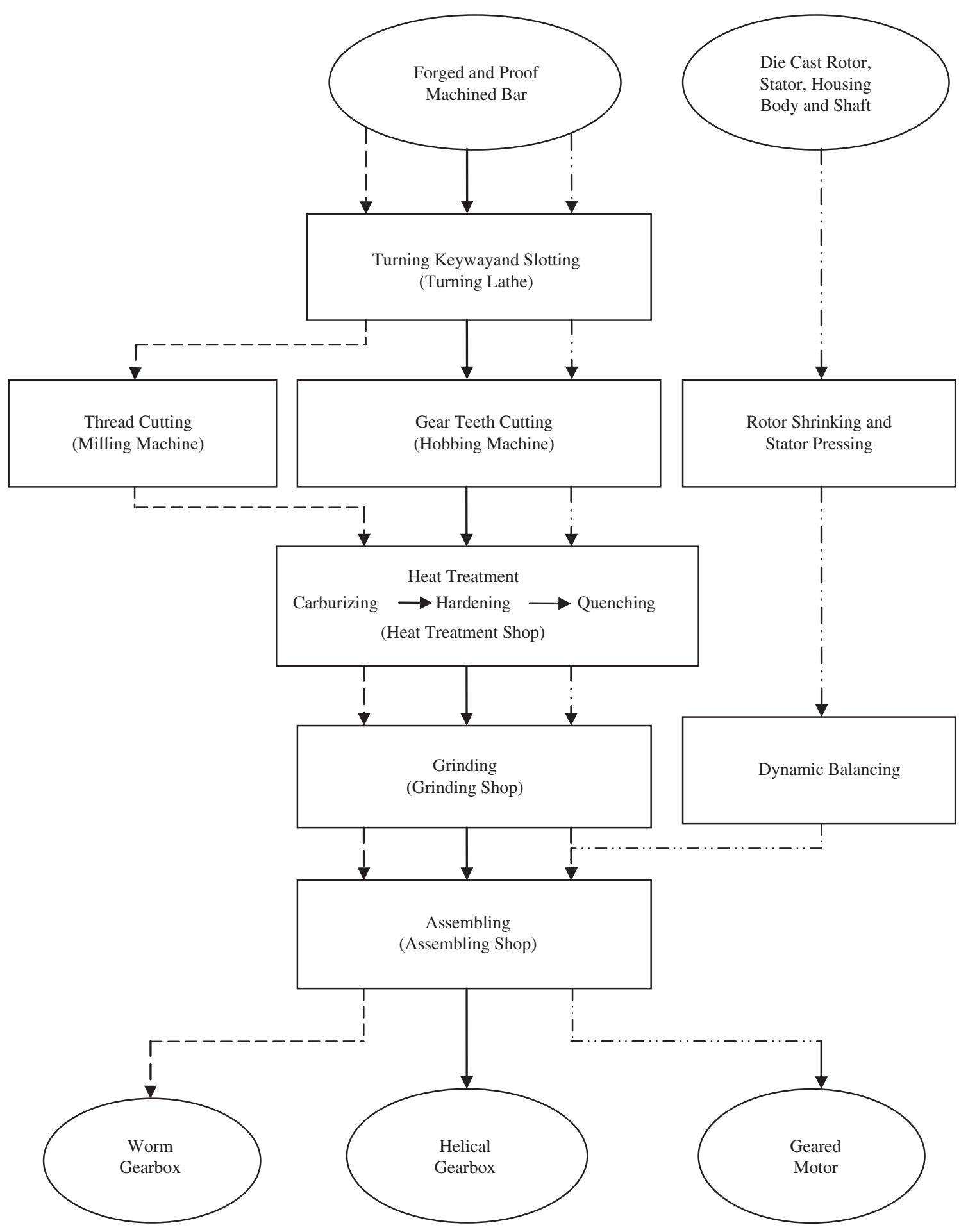

Figure 2. Basic manufacturing process of industrial gearbox and geared motor.

Table 2. Process mapping for manufacturing worm gearbox.

\begin{tabular}{lccccc}
\hline Operations & I1 & I2 & I3 & I4 & I5 \\
\hline Turning & NS & NS & NS & S & NS \\
Thread cutting & NS & NS & NS & S & NS \\
Heat treatment & S & S & S & S & NS \\
Grinding & NS & S & NS & NS & S \\
Assembling & NS & NS & S & NS \\
\hline
\end{tabular}


Table 3. Process mapping for manufacturing helical gearbox.

\begin{tabular}{lcccccc}
\hline Operations & I1 & I2 & I3 & I4 & I5 & I6 \\
\hline Turning & NS & NS & NS & S & NS & S \\
Teeth cutting & NS & NS & NS & S & NS & S \\
Heat treatment & S & S & S & NS & S & S \\
Grinding & NS & S & S & S & S & NS \\
Assembling & NS & NS & NS & NS
\end{tabular}

Table 4. Process mapping for manufacturing geared motor*.

\begin{tabular}{lllllcc}
\hline Operations & I1 & I2 & I3 & I4 & I5 & I6 \\
\hline Shrinking & NS & NS & NS & NS & NS & S \\
Pressing & NS & NS & NS & NS & S & S \\
Assembling & NS & NS & NS & NS & S & NS \\
\hline
\end{tabular}

* Common steps are avoided.

S and NS stand for "significant" and "not significant" respectively.

Table 5. Pairwise comparison matrix for priority ordering the EPIs.

\begin{tabular}{lccccccc}
\hline With respect to objective & I1 & I2 & I3 & I4 & I5 & I6 & Eigenvectors \\
I1 & 1 & 2 & 6 & $1 / 2$ & 4 & 5 & 0.262 \\
I2 & & 1 & 5 & $1 / 3$ & 3 & 4 & 0.174 \\
I3 & & 1 & $1 / 7$ & $1 / 3$ & $1 / 2$ & 0.036 \\
I4 & & & 1 & 5 & 6 & 0.393 \\
I5 & & & & 1 & 2 & 0.081 \\
I6 & & & & 1 & 0.053 \\
\hline
\end{tabular}

$\mathrm{CI}=0.033$ and $\mathrm{CR}=0.026<0.1$.

Table 6. Solid waste generation level of the plant.

\begin{tabular}{lccr}
\hline Parameters/indicators & Current year (2012) (in MT) & Previous year (2011) (in MT) & Avg. of last five years (in MT) \\
\hline Waste from machining & 22.12 & 20.70 & 21.40 \\
Grinding dust and others & 40.00 & 38.50 & 39.22 \\
Total solid waste & 62.12 & 59.20 & 60.62 \\
\hline
\end{tabular}

pairwise comparison on a 1-9 point scale with respect to the objective. AHP is chosen for the current case study due to its simplicity, flexibility and logical consistency. The values for pairwise comparison are selected by mutual understanding of the decision makers. CR value is also computed and found less than 0.1 , confirming the consistency of the judgment of the decision makers. Table 5 reflects that solid waste generation level (weightage 0.393) is the main CECMI for the present industrial gearbox manufacturing organization followed by stack emission characteristics (weightage 0.262), fugitive air characteristics (weightage 0.174) and noise intensity level (weightage 0.081). Energy consumption (weightage 0.053) and wastewater characteristics (weightage 0.036 ) are not critical to environmentally conscious manufacturing for the current industrial gearbox manufacturing organization.

\subsubsection{Root causes of CECMls}

Solid waste generation may be considered as the most important environmental problem for the organization as found in the AHP analysis. The root cause is that every year a significant amount of solid waste is produced by the organization due to the production of continuous or discontinuous chips or swarf during machining and grinding operations (see Table 6). Presently the solid wastes are first dumped and then sent to the garbage without taking care of properly. For dumping the chips, space is consumed and they may create problem regarding safety due to sharpness and may act as deep splinters to penetrate the skin of the workers. It may also affect skin due to the contamination of cutting fluid or tramp oil, if not handled properly, causing an occupational and health risk.

Stack emission characteristics, being the second priority among the CECMIs. It may be further categorized into five sub-indicators, namely particular matters (in $\mathrm{mg} / \mathrm{Nm}^{3}$ ) $\left(\mathrm{I} 2_{1}\right)$, carbon dioxide (in \%) (I2 $)$, gas flows (in $\left.\mathrm{Nm}^{3} / \mathrm{hr}\right)\left(\mathrm{I} 2_{3}\right)$, particulate matters discharged (in $\mathrm{mg} / \mathrm{Nm}^{3}$ ) (I2 4 ) and fuel consumption (in lit/hr) $\left(\mathrm{I} 2_{5}\right)$. The main sources of these sub-indicators are two sets of diesel generator (1 and 2) and centrifugal furnaces (see Table 7).

Since $\mathrm{I} 2_{1}, \mathrm{I} 2_{2}, \mathrm{I} 2_{3}$ and $\mathrm{I} 2_{4}$ are the outputs of the energy generation system the desired values of these indicators should be as high as possible according to the norm of DEA. However, 
Table 7. Stack emission characteristics of the plant.

\begin{tabular}{|c|c|c|c|c|c|}
\hline Energy sources & $\mathrm{I} 2_{1}$ & $\mathrm{I} 2_{2}$ & $\mathrm{I} 2_{3}$ & $\mathrm{I} 2_{4}$ & $\mathrm{I} 2_{5}$ \\
\hline D.G. set 1 & 63.75 & 8.20 & 268.19 & 0.017 & 20 \\
\hline D.G. set 2 & 78.06 & 9.00 & 2387.85 & 0.186 & 70 \\
\hline Centrifugal furnaces & 44.74 & 7.40 & 528.84 & 0.023 & 10 \\
\hline
\end{tabular}

Table 8. CCR and BCC values for the energy sources.

\begin{tabular}{|c|c|c|c|c|c|c|c|}
\hline Energy sources & $\mathrm{I} 2_{1}$ & $\mathrm{I} 2_{2}$ & $\mathrm{I} 2_{3}$ & $\mathrm{I} 2_{4}$ & $\mathrm{I} 2_{5}$ & CCR & $\mathrm{BCC}$ \\
\hline D.G. set 1 & 65.8 & 66.7 & 91.6 & 92.5 & 20 & 0.549 & $\overline{1.000}$ \\
\hline D.G. set 2 & 58.2 & 63.4 & 25.0 & 17.7 & 70 & 0.130 & 0.143 \\
\hline Centrifugal furnaces & 76.0 & 69.9 & 83.4 & 89.8 & 10 & 1.000 & 1.000 \\
\hline
\end{tabular}

Table 9. Fugitive air characteristics of the plant.

\begin{tabular}{lcccc}
\hline Name of plant areas & $\mathrm{I} 3_{1}$ & $\mathrm{I}_{2}$ & $\mathrm{I}_{3}$ & $\mathrm{I} 3_{4}$ \\
\hline Gear cutting section & 157 & 54 & 5 & 23 \\
Heavy eng. section & 274 & 178 & 6 & 24 \\
Heat treatment shop & 417 & 258 & 6 & 25 \\
\hline
\end{tabular}

Table 10. Noise intensity level of the plant.

\begin{tabular}{lcc}
\hline Locations/area & Time of sampling & $\begin{array}{c}\text { Equivalent sound } \\
\text { intensity level dB(A) }\end{array}$ \\
\hline Heavy eng. section & 12 noon & 78.53 \\
Power generation room & 12 noon & 89.57 \\
Gear cutting section & 12 noon & 79.30 \\
Main gate & 12 noon & 66.25 \\
\hline
\end{tabular}

from practical experience, it is quite clear that the desired values of the mentioned indicators must be as less as possible. For this reason, these values may be expressed in terms of (100-\% value of the respective indicator of total contribution) as shown in Table 8 to find out the CCR and BCC values as mentioned in the study Section 3.

CCR values reflect that diesel generator (set 2) is the main source (efficiency 0.130 ) to determine the stack emission characteristics followed by diesel generator (set 1). BCC values also show that diesel generator (set 2) is the major source (efficiency 0.143 ) to influence the stack emission characteristics.

Fugitive air characteristics, being the third most important CECMI as found from AHP analysis. It may be further categorized into four sub-indicators, namely suspended particular matters or SPM (in $\left.\mu \mathrm{g} / \mathrm{m}^{3}\right)\left(\mathrm{I}_{1}\right)$, residual particular matters or RPM (in $\mu \mathrm{g} / \mathrm{m}^{3}$ ) $\left(\mathrm{I}_{2}\right.$ ), sulphur dioxide or $\mathrm{SO}_{2}$ (in $\mu \mathrm{g} / \mathrm{m}^{3}$ ) $\left(\mathrm{I}_{3}\right)$, and nitrogen oxide or $\mathrm{NO}_{\mathrm{X}}$ (in $\left.\mu \mathrm{g} / \mathrm{m}^{3}\right)\left(\mathrm{I}_{4}\right)$. Basically gear cutting section, heavy engineering section and heat treatment shop are the major sources of fugitive air characteristics. From Table 9, it can be seen that the main source of fugitive air pollution is heat treatment shop followed by heavy engineering section and gear cutting section respectively.

Noise intensity level is another CECMI for the current industrial gearbox manufacturing organization. Power generation room, in particular, due to the use of the diesel generators exceeds even $89 \mathrm{~dB}(\mathrm{~A})$, creating a serious problem.
Gear cutting, heavy engineering and grinding sections are also considered as noisy area of the plant (see Table 10). Noise may also generate from dust extraction system and material handling equipments. If machine tools are not properly clamped, noise may create affecting the life of the machine tool and damaging the quietness of the workplace.

\subsection{Suggestion of possible alternative(s) to improve environmental performance}

As prevention of many kinds of pollution with the use of cleaner technologies is the cornerstone to implement successful environmental policy, in this section, some possible alternative solutions/strategic alternatives are proposed against the root causes with the help of state-of-the-art literature (which may be considered feasible for the current organization). These state-of-the-art techniques are critically appraised to understand their potentiality for the current organization [36-41].

\subsubsection{Solutions/strategic alternatives for solid waste generation}

Solid waste generation level, being the most important CECMI and significant environmental problem, may be taken care of by remanufacturing or recycling. If there is any blow hole in phosphor-bronze (P-B) rim at the time of worm gear box manufacturing, it may be melted to remanufacture. In order to make recycling possible efficient chip management system is required which may be performed through the following steps (see Figure 3):

Step 1: Proper suction system is required to collect the chips. Automatic extension or retraction may save time. The suctioning instrument or vacuum cleaner should be compatible with tool changing station and precision sensor without generating noise.

Step 2: Cutting fluid or tramp oil contaminated metal chips should be made oil/fluid free with the help of a centrifuge driven by an electric motor while putting an object in rotation around a fixed axis, applying a perpendicular force to the axis. Chips weight may be made up of up to $25 \%$ fluids adhering to the 


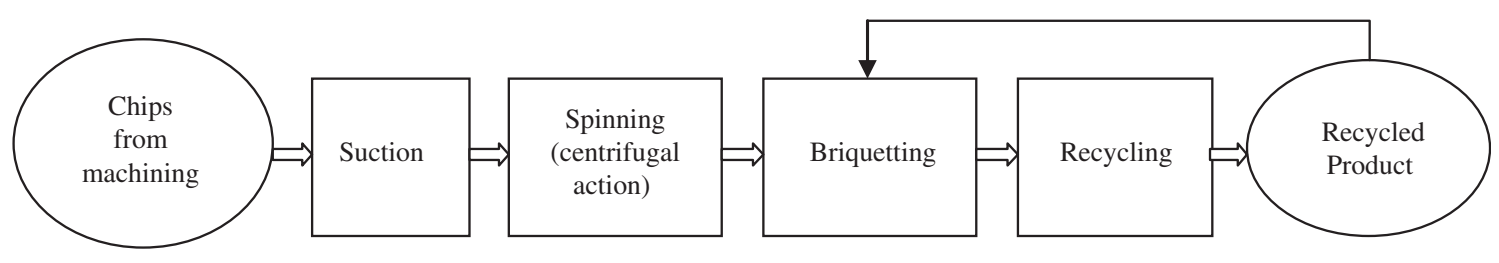

Figure 3. Solid waste management.

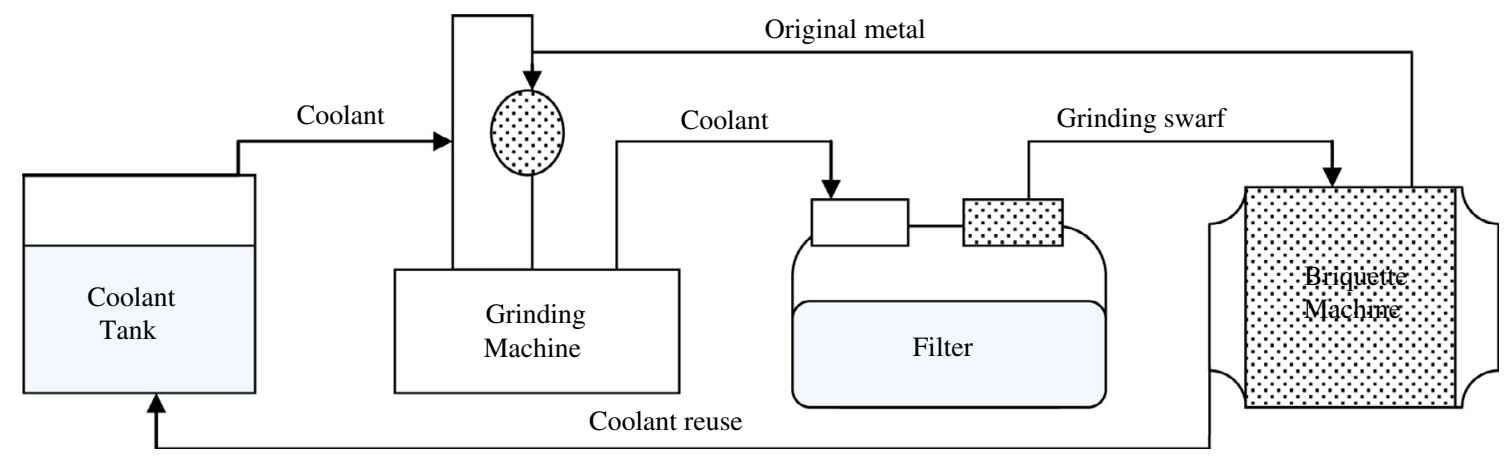

Figure 4. Proposed grinding sludge treatment.

surfaces, thus cutting fluids need to be reclaimed in order to reduce the amount of required cooling agents. Chips earn a higher scrap price when converted into the form of briquettes.

Step 3: Since continuous chips are produced during machining to manufacture industrial gearbox, it may acquire a huge space and frequently overfilling the chipcontainer. Due to this reason, chip-breaker is used to break the chips, converting into more manageable waste requiring less space. However, in case of grinding operation, chip-breaker is not required as grinding produces discontinuous chips in the form of dust.

Step 4: Now the broken chips in the form of briquettes may be recycled to produce various types of products used for different purpose depending on the material and quality of the chip. Different materials need to be segregated so that they cannot mix up.

Regarding safety issue, automated chip handling systems may be employed minimizing some of the safety issues involved with handling chips; however it requires high initial investment. Automated chip handling system is better than manual handling of chips. However, if manual handling is done, it must be performed with thick gloves going above the wrist. Regarding rust prevention, water soluble cutting oils like semi-synthetics may be used leaving a protective coating on chips to act as rust inhibitors.

In case of grinding swarf/chips, it may contain grinding sludge (metallic components), coolant (oil-based or waterbased) and a small amount of grinding powder. Applying typical cost-efficient Briquette technology originally developed by Nakamura, coolant may be separated from the chip and metallic components are solidified into briquettes, making both the coolant and metallic components ready to use again (see Figure 4) [36].

\subsubsection{Solutions/strategic alternatives for stack emission}

Stack emission characteristics, being the second most important CECMI and significant environmental problem, diesel generators, set 2 in particular may be replaced by inflation proof solar power generator using photovoltaic (PV) technology. Liquefied Petroleum Gas (LPG) may be used to help lower carbon dioxide, carbon monoxide and non-methane hydrocarbon emissions. Renewable energy sources like biofuels (such as: dimethyl ether or DME, algae-based biodiesel) may also be used to improve the stack emission characteristics of the plant in long run. Natural gas, being the cleanest burning fossil fuel, may emit less carbon dioxide than diesel. From natural gas, methanol may be prepared and used to act as a diesel substitute in order to achieve high performance and safety benefits. Methanol is available as M85 (a mixture of 85 per cent methanol and 15 per cent unleaded petrol) or M100 to reduce the air pollution. While Methanol's advantages include lower emissions, higher performance and lower risk of flammability, the downside involves producing a high amount of formaldehyde in emissions [28, 42, 43]. Since most of the energy sources have advantages as well as disadvantages, hence hybrid system using more than one energy sources may be considered as the proper alternative to get optimal efficiency with least air pollution [44-47]. Proper air pollution control devices like electrostatic precipitators, fabric filters/bag houses, wet scrubbers and cyclone separators should be used by the industrial gearbox manufacturing organization. In order to control gaseous and vapour pollutants, thermal oxidizers, catalytic reactors, carbon adsorbers, absorption towers and biofilters may be used [48]. 
Table 11. Expected outcomes with respect to the implementation of the strategic alternatives.

\begin{tabular}{|c|c|c|c|c|}
\hline $\begin{array}{l}\text { Environmental } \\
\text { challenges }\end{array}$ & Major sources & $\begin{array}{c}\text { Impact/risks } \\
\text { assessment }\end{array}$ & $\begin{array}{c}\text { Strategic } \\
\text { alternatives }\end{array}$ & $\begin{array}{l}\text { Expected } \\
\text { outcomes }\end{array}$ \\
\hline $\begin{array}{l}\text { Solid Waste } \\
\text { Generation }\end{array}$ & $\begin{array}{l}\text { Chips/swarf } \\
\text { generated from } \\
\text { machining }\end{array}$ & $\begin{array}{l}\text { Environmental } \\
\text { damage } \\
\text { (Land pollution } \\
\text { basically) } \\
\text { Occupational } \\
\text { risk due to lack } \\
\text { of safety }\end{array}$ & $\begin{array}{l}\text { Solid waste management } \\
\text { by recycling with proper } \\
\text { handling of chips/swarf }\end{array}$ & $\begin{array}{l}\text { Making money } \\
\text { Better occupational health } \\
\text { and safety Less space } \\
\text { consumption } \\
\text { for storage }\end{array}$ \\
\hline \multirow[t]{3}{*}{$\begin{array}{l}\text { Air Pollution } \\
\text { (stack emission } \\
\text { characteristics and } \\
\text { fugitive air } \\
\text { characteristics) }\end{array}$} & $\begin{array}{l}\text { Heat treatment } \\
\text { shop }\end{array}$ & $\begin{array}{l}\text { GHG emission due to } \\
\text { carburizing and } \\
\text { quenching } \\
\text { (salt bath) } \\
\text { Occupational risk due } \\
\text { to smoke }\end{array}$ & Plasma carburization & $\begin{array}{l}\text { Reduced GHG emission } \\
\text { Elimination of oil waste } \\
\text { Reduction of production time } \\
\text { Less dimensional alterations } \\
\text { and distortions } \\
\text { Better workplace } \\
\text { Less energy consumption }\end{array}$ \\
\hline & $\begin{array}{l}\text { Diesel generator } \\
\text { sets (particularly } \\
\text { set 2) }\end{array}$ & $\begin{array}{l}\text { GHG emission } \\
\text { Occupational risk } \\
\text { due to smoke }\end{array}$ & $\begin{array}{l}\text { Hybrid energy system } \\
\text { including at least one } \\
\text { renewable energy source }\end{array}$ & $\begin{array}{l}\text { Less GHG emission } \\
\text { Better workplace }\end{array}$ \\
\hline & $\begin{array}{l}\text { High capacity } \\
\text { centrifugal } \\
\text { furnaces }\end{array}$ & $\begin{array}{l}\text { GHG emission } \\
\text { Occupational risk } \\
\text { due to smoke }\end{array}$ & $\begin{array}{l}\text { Proper utilization of } \\
\text { furnaces, installation of } \\
100 \mathrm{~kg} \text { furnaces }\end{array}$ & $\begin{array}{l}\text { Reduced GHG emission } \\
\text { Better workplace }\end{array}$ \\
\hline \multirow[t]{2}{*}{ Noise Pollution } & $\begin{array}{l}\text { Machining, } \\
\text { grinding, } \\
\text { hammering and } \\
\text { diesel generator }\end{array}$ & $\begin{array}{l}\text { Miscommunication, } \\
\text { stress, anxiety and } \\
\text { hearing loss }\end{array}$ & $\begin{array}{l}\text { Preventive maintenance } \\
\text { of machines }\end{array}$ & $\begin{array}{l}\text { A significant amount of } \\
\text { sound/noise reduction may } \\
\text { be achievable }\end{array}$ \\
\hline & & & $\begin{array}{l}\text { Replacing the bearings } \\
\text { of fan } \\
\text { Tightening loose fittings }\end{array}$ & \\
\hline
\end{tabular}

\subsubsection{Solutions/strategic alternatives for fugitive emission}

Regarding fugitive air characteristics of the plant, heat treatment shop should be taken care of properly to control the level of fugitive air characteristics as during carburizing, a number of GHG including methanol, acetone and quenching oil vapours are formed polluting air and affecting occupational health for the workers. Plasma carburization may be considered as an effective alternative or solution as it may lead to eliminate oil wastes reducing energy consumption, production time and dimensional alteration and distortion [49, 50]. In heavy engineering and gear cutting section, more number of CNC machines may be employed to reduce the fugitive emission. Non-flammable, low percentage methane and nitrogen mixtures may be used during furnace injection by a novel, non-thermal electric discharge (cold plasma ${ }^{1}$ ) method [51]. Most of the CNC machines need to be confined by polycarbonate glasses to prevent the effect of splashing of cutting fluids during machining.

\subsubsection{Solutions/strategic alternatives for noise generation}

To address noise generating issue, proper preventive maintenance is required to obtain quiet workplace. To block the transmission path of noise from one section to another section,

\footnotetext{
${ }^{1}$ Cold plasma may be any plasma, not being in thermodynamic equilibrium either because of the difference in temperature between the ion and the electron, or because of the difference between its velocity distribution and Maxwell-Boltzmann distribution.
} 
acoustic curtain may be used. Sound-insulating walls may be installed around the noise generation source to prevent noise pollution.

Another example of noise control along the transmission path may be a fully enclosed workstations fitting with full core doors and double glazed windows. Noise may be reduced significantly by using glass panels of two thicknesses, a thicker panel on the outside and a thinner one on the inside, with a vacuum gap. Workstations or sections may be rearranged by special bays made of solid steel plate on the outside, covered with perforated steel sheet on the inside may be constructed where all welding, grinding and hammering take place. To provide a suitable environment for workshop paperwork, offices may be fully covered with laminated glass panels to reduce the noise level up significantly inside the office with all the windows closed. Dust extractors may be mounted on cushions. Old motors may be replaced and loose fittings should be tightened. Engineering noise may be controlled at the source by proper clamping system and monitoring of production machinery. The grinding machines may be mounted using rubber mounts [23, 24].

The expected outcomes with respect to the implementation of the solutions/strategic alternatives are listed in Table 11.

\section{Conclusions}

In this paper, an attempt has been made to understand the environmental complexities involved in industrial gearbox manufacturing. The contribution of this paper is that it finds out the root causes of environmental problems during manufacturing and describes the solutions/strategic alternatives for the industrial gearbox manufacturing organization with expected outcomes. It also critically discusses the available literature regarding environmental solutions for industrial gearbox manufacturing. To find out the root causes present research work utilizes multi-criteria decision analysis tools. It is found from the analysis that air pollution and noise pollution are the major factors to be considered for the present organization. This research work may help the organization to develop or change their current manufacturing strategy in order to produce environment friendly. The expected outcomes may be verified if the industrial gearbox manufacturing organization implements the suggested alternatives/solutions explained in this paper.

\section{References}

1. D.T. Allen, D.R. Shonnard, Sustainability in chemical engineering education: identifying a core body of knowledge, AlChE (American Institute of Chemical Engineers) Journal, https:/workspace.imperial.ac.uk/ceFluidMechanics/Public/13877_ fta.pdf (accessed on dated 27th May, 2013).

2. M. Gaussin, G. Hub, S. Abolghasem, S. Basu, M.R. Shankar, B. Bidanda, Assessing the environmental footprint of manufactured products: a survey of current literature, International Journal of Production Economics 146 (2013) 515-523.

3. A. Swain, Climate change connection, Winnipeg, Manitoba, Canada 1 (July, 2006), http://www.climatechangeconnection.org/ resources/documents/business_guide.pdf(dated 7th May, 2013).
4. A.D. Jayal, F. Badurdeen, O.W. Dillon Jr, I.S. Jawahir, Sustainable manufacturing: modeling and optimization challenges at the product, process and system levels, CIRP Journal of Manufacturing Science and Technology 2 (2010) 144-152.

5. J. Sarkis, Manufacturing strategy and environmental consciousness, Technovation 15 (1995) 79-97.

6. CPCB (Central Pollution Control Board) Report, Guidelines for ambient air quality monitoring (April, 2003), http:// www.cpcb.nic.in/newitems/7.pdf (accessed on dated 15th June, 2013).

7. CPCB (Central Pollution Control Board) Report, Guidelines for water quality management (January, 2008), http://www.cpcb.nic.in/upload/NewItems/NewItem_97_ guidelinesofwaterqualitymanagement.pdf (accessed on dated 19th July, 2013).

8. G. Singh, R.M. Belokar, Lean manufacturing implementation in the assembly shop of tractor manufacturing company, International Journal of Innovative Technology and Exploring Engineering 1 (2012) 71-74.

9. P. Sen, P.K. Ray, S.K. Ghosh, Environmental performance measurement and evaluation for manufacturing organizations: a review and reflection, Proceedings of the International Conference on Managing the Asian Century (ICMAC) (2013) 193-199.

10. Energetics, Inc. Gear industry vision (September, 2004), http:// www.geartechnology.com/issues/0907x/sepoct07.pdf (accessed on dated 18th July, 2013).

11. A.M. Deif, A system model for green manufacturing, Journal of Cleaner Production 19 (2011) 1553-1559.

12. J. Rawlings, P. Coker, J. Doak, B. Burfoot, Do smart grids offer a new incentive for SME carbon reduction? Sustainable Cities and Society 10 (2014) 245-250.

13. N. Ramzan, S. Degenkolbe, W. Witt, Evaluating and improving environmental performance of HC's recovery system: a case study of distillation unit, Chemical Engineering Journal 140 (2008) 201-213.

14. M. Zackrisson, C. Rocha, K. Christiansen, A. Jarnehammar, Stepwise environmental product declarations: ten SME case studies, Journal of Cleaner Production 16 (2008) 1872-1886.

15. A. Zorpas, Environmental management systems as sustainable tools in the way of life for the SMEs and VSMEs, Bioresource Technology 101 (2010) 1544-1557.

16. E. Claver, M.D. López, J.F. Molina, J.J. Tari, Environmental management and firm performance: a case study, Journal of Environmental Management 84 (2007) 606-619.

17. S.G. Azevedo, H. Carvalho, V.C. Machado, The influence of green practices on supply chain performance: a case study approach, Transportation Research Part E 47 (2011) 850-871.

18. S.X. Zeng, X.H. Meng, R.C. Zeng, C.M. Tam, V.W.Y. Tam, T. Jin, How environmental management driving forces affect environmental and economic performance of SMEs: a study in the Northern China district, Journal of Cleaner Production 19 (2011) 1426-1437.

19. International Finance Corporation (IFC) environmental, health, and safety guidelines report (April, 2007), http://www.ifc. org/wps/wcm/connect/532ff4804886583ab4d6f66a6515bb18/ 1-1\%2BAir\%2BEmissions $\% 2$ Band $\% 2$ BAmbient $\% 2$ BAir $\%$ 2BQuality.pdf?MOD=AJPERES (accessed on dated 29th May, 2013).

20. A.K. Chambers, M. Strosher, T. Wootton, J. Moncrieff, P. McCready, Direct measurement of fugitive emissions of 
hydrocarbons from a refinery, Journal of Air and Waste Management Association 58 (2008) 1047-1056.

21. R. Devi, R.P. Dahiya, COD and BOD removal from domestic wastewater generated in decentralised sectors, Bioresource Technology 99 (2008) 344-349.

22. B.J.S. Uiterkamp, H. Azadi, P. Ho, Sustainable recycling model: a comparative analysis between India and Tanzania Resources, Conservation and Recycling 55 (2011) 344-355.

23. Department of Consumer and Employment Protection, Government of Western Australia, Successful noise management in manufacturing (February, 2006), http://www.commerce. wa.gov.au/worksafe/PDF/Hazard_identification/Successful_ noise_man.pdf (accessed on dated 19th September, 2013).

24. Department of Justice and Attorney-General, Queensland Government, Workplace Health and Safety (January, 2010), http://www.deir.qld.gov.au/workplace/index.htm\#.UxqR68A1MZs (accessed on dated 19th September, 2013).

25. K. Fang, N. Uhana, F. Zhaob, J.W. Sutherland, A new approach to scheduling in manufacturing for power consumption and carbon footprint reduction, Journal of Manufacturing Systems 30 (2011) 234-240.

26. B. Sundarakani, R. Souza, M. Goh, S.M. Wagner, S. Manikandan, International Journal of Production Economics 128 (2010) 43-50.

27. B.W. Ang, P.W. Lee, Decomposition of industrial energy consumption: the energy coefficient approach, Energy Economics 18 (1996) 129-143.

28. U.S. Environmental Protection Agency Reportm, Energy trends in selected manufacturing sectors: opportunities and challenges for environmentally preferable energy outcomes (March, 2007), http://www.epa.gov/sectors/pdf/energy/report.pdf (accessed on dated 12th June, 2013).

29. J.P. Santos, M. Oliveira, F.G. Almeida, J.P. Pereira, A. Reis, Improving the environmental performance of machine-tools: influence of technology and throughput on the electrical energy consumption of a press-brake, Journal of Cleaner Production 19 (2011) 356-364.

30. T.L. Saaty, The analytic hierarchy process, McGraw-Hill, New York, 1980.

31. T.L. Saaty, How to make a decision: the analytic hierarchy process, European Journal of Operational Research 48 (1990) 9-26.

32. W.D. Cook, K. Tone, J. Zhu, Data envelopment analysis: prior to choosing a model, Omega 44 (2014) 1-4.

33. J. Doyle, R. Green, Efficiency and cross-efficiency in DEA: derivations, meanings and uses, Journal of the Operational Research Society 45 (1994) 567-578.

34. J. Sarkis, A methodological framework for evaluating environmentally conscious manufacturing programs, Computers and Industrial Engineering 36 (1999) 793-810.

35. M. Omid, F. Ghojabeige, M. Delshad, H. Ahmadi, Energy use pattern and benchmarking of selected greenhouses in Iran using data envelopment analysis, Energy Conversion and Management 52 (2011) 153-162.

36. K. Nakamura, Introduction of grinding swarf recycling, NTN technical review, engineering department, Unitop Corporation
(2004), http://www.ntn.co.jp/english/products/review/pdf/ NTN_TR71_en_P080.pdf (accessed on dated 18th July, 2013).

37. J. Gronostajski, A. Matuszak, The recycling of metals by plastic deformation: an example of recycling of aluminium and its alloys chips, Journal of Materials Processing Technology 92-93 (1999) 35-41.

38. Acculube Accurate Lubricant and Metalworking Fluids, Inc., http://www.acculube.com (accessed on dated 17th August, 2013).

39. Datron Smart Manufacturing Solutions, http://www. datron.co.in (accessed on dated 17th August, 2013).

40. Lubriserv Ltd, http://www.lubriserv.com (accessed on dated 18th August, 2013).

41. Indass metalworking fluid recycling and management equipment (2011), http://www.newmoa.org/prevention/topichub/23/ newmoamanualch1.pdf (accessed on dated 18th August, 2013).

42. G. Knothe, R.O. Dunn, M.O. Bagby, Biodesel: the use of vegetable oils and their derivatives as alternative diesel fuels, fuels and chemicals from biomass, 172-208, http://www. siame.gov.co/siame/documentos/documentacion/mdl/03_VF_ Bibliografia/Biodiesel/use_of_vegetable_oils.pdf.

43. Y. Ali, M.A. Hanna, Alternative diesel fuels from vegetable oils, Bioresource Technology 50 (1994) 153-163.

44. S. Yamamoto, J.S. Park, M. Takata, K. Sasaki, T. Hashimoto, Basic study on the prediction of solar irradiation and its application to photovoltaic-diesel hybrid generation system, Solar Energy Materials and Solar Cells 75 (2003) 577-584.

45. H.S. Jacobus, K. Kiger, Solar-Diesel hybrid power system optimization and experimental validation (2010) http://drum. lib.umd.edu/bitstream/1903/11276/1/Jacobus_umd_0117N_ 11857.pdf

46. K. Kusakana, H.J. Vermaak, Hybrid diesel generator/renewable energy system performance modeling, Renewable Energy 67 (2014) 97-102.

47. D. Yamegueu, Y. Azoumah, X.P.N. Zongo, Experimental study of electricity generation by Solar PV/diesel hybrid systems without battery storage for off-grid areas, Renewable Energy 36 (2011) 1780-1787.

48. Air and waste management association report, Air pollution emission control devices for stationary sources (April, 2007), http://events.awma.org/files_original/ControlDevicesFactSheet07. pdf (accessed on dated 29th May, 2013).

49. Axon Technologies Consult Report, Plasma carburizing with high pressure gas quenching (March 26, 1997), http:// cordis.europa.eu/documents/documentlibrary/26817631EN6.pdf (accessed on dated 19th May, 2013).

50. Excerpts, pollution prevention in machining and metal fabrication (March, 2001).

51. Z. Zurecki, X. Wang, Atmosphere carburizing using electric discharge-activated nitrogen-natural gas mixtures, http://www.airproducts.com/ /media/downloads/white-papers/ A/en-atmos-carburizing-using-electric-discharge-activatednitrogen-natural-gas-mixtures-330-10-011-us.pdf (accessed on dated 05th March, 2014). 


\section{Appendix A}

\section{Workshop on environmental conscious manufacturing programmes: a questionnaire based interaction}

During the past half an hour of the lecture session, you have come across a number of issues related to climate change due to environmental performance of SMEs. These issues are relevant for any type of manufacturing industry. The objective of this questionnaire-based interaction is to find out the strength and future scope of improvement of the environmental performance of your company.

We have framed 14 specific questions on all these issues. It will be very nice of you if we get your valuable responses or suggestions on all these questions.

Question-1. Your manufacturing system may be producing a number of quality products. Name the products.

Question-2. State briefly the manufacturing processes to produce these products.

Question-3. Do you consider your production process as environment friendly? If yes, why? If not, why not?

Question-4. Which indicators or factors may be considered to measure the environmental performance of your company and why?

Question-5. While you measure operating performance for your plant/manufacturing unit, do you consider rejects/wastes in the performance measures? If yes, what are those? Please identify them.

Question-6. In your manufacturing/production system, identify any the stages/work areas where waste reduction is a problem.

Question-7. You have already identified three stages/work areas where waste generation is a problem. Do you think that this problem is related to any one or more of the following factors? Tick the factor(s) as appropriate.

(i) Technology ( )

(ii) Raw Materials ( )

(iii) Settings ( )

(iv) Aging/Outdated ( )
Question-8. You may be taking adequate control measures to check pollution at your workplace. However, in spite of your best effort, there could be few types of pollution which are directly or indirectly affecting your operational performance. Please mention the possible solutions against the following types of pollution.

(i) Air Pollution:

(ii) Water Pollution:

(iii) Land Degradation:

(iv) Any other kinds of pollution:

Question-9. You are definitely measuring or willing to measure the level of pollution. Please mention the kinds of measures and the measurement systems you have currently being using.

Question-10. Where, in your manufacturing/production system are pollution problems significant?

Question-11. What are the quality management-related standards you have been following currently?

Question-12. For improving overall productivity of your manufacturing/production system, "reuse" and "recycling" are recommended means. This ensures acceptable/minimum production cost. Explain, in brief (within 3 to 4 sentences), to what extent this means is used in your manufacturing/ production system effected?

Question-13. You are aware of the complexity of the problem related to GM \& GSCM. Please provide your suggestions for improving the quality of workplace/work-life in this respect.

Question-14. Do you have any idea to solve the current environmental problems faced by your company? If yes, briefly explain them.

Thank you for your support and cooperation.

Please write your

Name:

Designation:

Affiliation: 


\section{Appendix B}

\section{Questionnaire for prioritization-ranking among the Environmental Performance Indicators (EPI)}

Please rate of a scale from 1 to $9(1,2,3,4,5,6,7,8$ and 9 for equal importance weak or slight importance, moderate importance, moderate plus importance, strong importance, strong plus importance, very strong or demonstrated importance, very very strong importance and extreme importance respectively) to indicate pairwise relationship. Mark the relative importance of the former indicator when compared to the later indicator on controlling environmental performance. I1, I2, I3, I4, I5 and I6 represent stack emission characteristics, fugitive air characteristics wastewater characteristics solid waste generation level sound intensity level and energy consumption respectively.

\begin{tabular}{|c|c|c|c|c|c|c|c|c|c|c|c|c|c|c|c|c|c|c|}
\hline Former indicator & & & & & & $\mathrm{nc}$ & rol & $\mathrm{g}$ et & on & & erf & nan & & & & & & Later indicator \\
\hline I1 & 9 & 8 & 7 & 6 & 5 & 4 & 3 & 2 & 1 & 2 & 3 & 4 & 5 & 6 & 7 & 8 & 9 & $\mathrm{I} 2$ \\
\hline I1 & 9 & 8 & 7 & 6 & 5 & 4 & 3 & 2 & 1 & 2 & 3 & 4 & 5 & 6 & 7 & 8 & 9 & I3 \\
\hline I1 & 9 & 8 & 7 & 6 & 5 & 4 & 3 & 2 & 1 & 2 & 3 & 4 & 5 & 6 & 7 & 8 & 9 & I4 \\
\hline I1 & 9 & 8 & 7 & 6 & 5 & 4 & 3 & 2 & 1 & 2 & 3 & 4 & 5 & 6 & 7 & 8 & 9 & I5 \\
\hline I1 & 9 & 8 & 7 & 6 & 5 & 4 & 3 & 2 & 1 & 2 & 3 & 4 & 5 & 6 & 7 & 8 & 9 & I6 \\
\hline I2 & 9 & 8 & 7 & 6 & 5 & 4 & 3 & 2 & 1 & 2 & 3 & 4 & 5 & 6 & 7 & 8 & 9 & I3 \\
\hline I2 & 9 & 8 & 7 & 6 & 5 & 4 & 3 & 2 & 1 & 2 & 3 & 4 & 5 & 6 & 7 & 8 & 9 & I4 \\
\hline $\mathrm{I} 2$ & 9 & 8 & 7 & 6 & 5 & 4 & 3 & 2 & 1 & 2 & 3 & 4 & 5 & 6 & 7 & 8 & 9 & I5 \\
\hline $\mathrm{I} 2$ & 9 & 8 & 7 & 6 & 5 & 4 & 3 & 2 & 1 & 2 & 3 & 4 & 5 & 6 & 7 & 8 & 9 & I6 \\
\hline I3 & 9 & 8 & 7 & 6 & 5 & 4 & 3 & 2 & 1 & 2 & 3 & 4 & 5 & 6 & 7 & 8 & 9 & I4 \\
\hline I3 & 9 & 8 & 7 & 6 & 5 & 4 & 3 & 2 & 1 & 2 & 3 & 4 & 5 & 6 & 7 & 8 & 9 & I5 \\
\hline I3 & 9 & 8 & 7 & 6 & 5 & 4 & 3 & 2 & 1 & 2 & 3 & 4 & 5 & 6 & 7 & 8 & 9 & I6 \\
\hline I4 & 9 & 8 & 7 & 6 & 5 & 4 & 3 & 2 & 1 & 2 & 3 & 4 & 5 & 6 & 7 & 8 & 9 & I5 \\
\hline I4 & 9 & 8 & 7 & 6 & 5 & 4 & 3 & 2 & 1 & 2 & 3 & 4 & 5 & 6 & 7 & 8 & 9 & I6 \\
\hline I5 & 9 & 8 & 7 & 6 & 5 & 4 & 3 & 2 & 1 & 2 & 3 & 4 & 5 & 6 & 7 & 8 & 9 & I6 \\
\hline
\end{tabular}

Cite this article as: Sen P, Pal P \& Roy M: An explorative study to enable environmentally conscious manufacturing for an industrial gearbox manufacturing organization. Manufacturing Rev. 2014, 1, 19. 